\title{
Effects of Yalom Group therapy on the Resilience and Meaning in Life of the Nurses in Covid-19 Centers
}

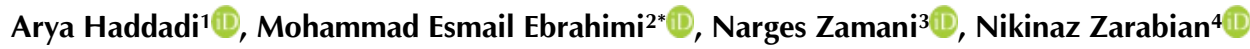 \\ 1 Department of Clinical Psychology, Faculty of Medical Science, Hamedan Branch, Islamic Azad University, \\ Hamedan, Iran \\ 2 Assistant Professor, Department of Psychology, Faculty of Humanities, Hamedan Branch, Islamic Azad \\ University, Hamedan, Iran \\ ${ }^{3}$ Assistant Professor, Department of Psychology, Faculty of Humanities, Najafabad Branch, Islamic Azad \\ University, Najafabad, Iran \\ ${ }^{4}$ Department of Clinical Psychology, Faculty of Medical Science, Sanandaj Branch, Islamic Azad University, \\ Sanandaj, Iran
}

\begin{abstract}
*Corresponding author:
Mohammad Esmail Ebrahimi, Assistan

Professor, Department of Psychology,

Faculty of Humanities, Hamedan

Branch, Islamic Azad University,

Hamedan, Iran

Tel: 09127849470

Email: Mse58_2007@yahoo.com
\end{abstract}

Received: 09 Nov. 2020

Accepted: 22 Mar 2021

ePublished: 01 Nov. 2021

\begin{abstract}
Background and Objective: This study aimed to analyze the effects of the Yalom group therapy on the resilience and meaning in life of the nurses fighting COVID-19.

Materials and Methods: This quasi-intervention pre-test post-test research was conducted with a control group. Statistical population of this study included all the nurses of the hospitals of Hamedan who cared for the COVID-19 patients in 2020. According to the inclusion and exclusion criteria, 32 nurses were randomly selected and divided equally into the intervention and control groups. The intervention group was treated by the Yalom group therapy for 10 sessions. Evaluation tools were the Connor-Davidson (2003) Resilience Questionnaire and The Meaning in Life Questionnaire of Steger et al. which were completed by both groups at pre-test and post-test stages. The data were analyzed using the multivariate analysis of covariance and univariate analysis of variance in SPSS software (version 24).

Results: The significance level of the difference between the mean scores of "meaning in life" was less than $0.05(\mathrm{P}<0.05)$. Hence, the difference between the means was significant and it can be said that the Yalom group therapy affects the meaning in life. According to the eta-squared value, the extend of this impact was about $64 \%$. Moreover, the difference between the mean of the resilience scores of the intervention and control group was 58.94 and the significance level of this value was less than 0.05 ( $F[1$ and 27$]=58.937, P=0.001)$. Therefore, the difference between the means of the resilience scores of the intervention and control groups was significant with $95 \%$ confidence. It can be said that the Yalom group therapy had a significant impact on the resilience of the nurses.

Conclusion: The results can be used to maintain and care for the mental health of nurses during severe disease epidemics, such as the Coronavirus epidemic.

Keywords: Coronavirus, Covid-19, Group therapy, Meaning in life, Nurse, Resilience
\end{abstract}

\section{Background}

Previous studies have reported that the medical staff, specifically people working in emergency, intensive care units, and infectious diseases wards, are more exposed to psychological side effects [1]. Excessive work pressure, long working hours, inadequate personal protective equipment, exaggerated media news, and feeling of lack of support can be pointed out as some of the causes of these adverse effects [2]. Frustration, exhaustion, and adaptation problems are the other consequences facing the medical staff [3].

The meaning in life can be considered as an essential psychological requirement and one of the main factors of wellbeing [4].

Having meaning in life refers to a state in which a person's perception of life experiences is based on the feeling that all the experiences are purposeful and formed in the direction of that purpose. While trying to search for the meaning refers to the effort and intensity of the desire of people to build, find, or discuss the meaning of life [5].

Some studies have shown that there is a significant and positive correlation among happiness, the meaning of life, and satisfaction of life [6]. Resilience is another important psychological factor that helps people protect themselves against internal and external stressors in difficult situations and employ better strategies for problem-solving [7].

Resilience makes a kind of positive adaption mechanism which engages multiple individual and social factors called "protective factors in person's empowerment and decreasing risk factors" [8]. It is 
worth noting that the lifestyles of people affect their level of resilience [9].

According to the provided definitions, maintaining and empowering these two factors are very essential for the improvement of the mental wellbeing of the medical staff, specifically the nurses who are at the forefront of the fight against the COVID-19 epidemic. Considering that group therapy can provide proper psychological services to a large number of nurses with a low number of specialists in a short period of time, our priority was group therapy. Moreover, the Yalom group therapy is used as our method due to its concentration on social support to increase resilience. In addition, it analyzes the emotions and behaviors of the members and can evaluate the meaning of life of the members.

Yalom, who is an existential psychiatrist and the pioneer of group therapy, founded his specific group intervention method based on the emphasis on the "Here and Now" process [10]. He defines this process as the nature of the relationships between individuals in their communication (i.e., the group members and the therapists) [10]. This intervention does not follow specific treatment methods and only focuses on dynamic currents in the group, such as emotional support, emotional feedbacks, and feeling of belonging to a safe group. Therefore, it can be useful to show the positive effect of rich and constructive relationships in a work environment with difficult situations (i.e., the COVID-19 epidemic in a hospital) on the mental health of the nurses.

\section{Objectives}

In this study, the hypothesis is that if the provision of this group therapy can increase the resilience and meaning in life, it can be a good option for nurses who are suffering from disappointment and mental frustration due to the high work pressure.

\section{Materials and Methods}

This quasi-intervention was performed based on a pretest-posttest design with a control group. The research statistical population included all the nurses of the hospitals in Hamedan. For the purposes of the study, 100 questionnaires were distributed in Fatemiyeh Hospital, Hamedan, Iran using the random sampling method. Finally, according to the inclusion and exclusion criteria, 32 nurses were selected and divided into two groups of 16 people: The inclusion criteria were: 1) caring for COVID-19 patients, 2) score of one lesser deviation in "CanerDavidson's Resilience Questionnaire" and "Steger's meaning in life questionnaire", 3) announcing readiness to attend the group therapy sessions continuously till the end of the research. On the other hand, the exclusion criterion was absence for more than two consecutive and three nonconsecutive sessions.

Measuring tools

The tools used in this research were:

\section{Connor Davidson Resilience Scale}

The total score of each subject is equal to the sum of the scores of each item. In 2003, Caner and Davidson reported the test-retest reliability of this questionnaire on 24 patients with generalized anxiety disorder and post-traumatic stress disorder at 0.87 [11]. This questionnaire is also standardized by Bigdeli (2013), and the results indicated that this questionnaire has a Cronbach's alpha of 0.89. Regarding its validity, factor analysis was used to calculate each score with the total score which showed that the coefficients of the items were 0.790.86 , except for three items [12].

\section{The Meaning in Life Questionnaire by Steger et al.}

The Meaning in Life questionnaire by Steger et al. is provided by Steger, Frazier, Oishi, and Kaler, to evaluate the existence of meaning and attempts to find it. The validity, reliability, and factor structure of the questionnaire have been examined in various studies with different samples [5]. Moreover, the subscale reliability values of the "existence of meaning" and "search for meaning" were 0.70 and 0.73 , respectively [5]. In the research by Peymanfar et al., the reliability coefficient of the meaning in life questionnaire was 0.89 using the Cronbach's alpha formula [13]. In a research performed by Mesrabadi et al. (2013), the construct and diagnostic validity of this questionnaire were evaluated and reported as favorable [14].

Group therapy is a kind of psychotherapy, which consists of one or more therapists who work with several people at the same time. Regarding the research method, first, permission was obtained from the Research Council of Hamadan University, Hamedan, Iran. Afterward, the research process was explained to the participants, and they completed the questionnaires. It should be mentioned that only 38 nurses were selected according to the inclusion and exclusion criteria and considering 1 lower deviation score. The nurses were divided into two groups of intervention and control. The intervention group was treated by the Yalom group psychotherapy for 10 sessions and during this period, no training was provided for the control group. Finally, given the reduction, the subjects were reduced to 32 people and two groups of 16 people. The training process 
was implemented based on the therapeutic protocol derived from The Theory and Practice of Group Psychotherapy book by Yalom and Leszcz [10]. The training process is summarized in Table 1:
The protocol of Yalom group therapy sessions has been designed based on the books: The Theory and Practice of Group Psychotherapy (Yalom and Leszcz, 2020), and The Schopenhauer Cure (2005) [10,15].

Table 1. Protocol of Yalom group therapy sessions.

\begin{tabular}{|c|c|c|}
\hline Session & Content & Duration \\
\hline First & $\begin{array}{c}\text { Introduction of the group leader } \\
\text { Statement of the objectives of the session } \\
\text { Some introduction about group therapy and its different types } \\
\text { Encouragement of the members to introduce themselves }\end{array}$ & 90 minutes \\
\hline Second & $\begin{array}{l}\text { Reception feedbacks from the members on the previous session } \\
\text { Explanation and comparison of the "content" and "process" by the group leader } \\
\text { Explanation about the group norms by the group leader and encouragement of the members to follow them } \\
\text { Encouragement of the group members to give feedback to the other members considering the group norms } \\
\text { Reception of the final feedback on the session and conclusion }\end{array}$ & 90 minutes \\
\hline Third & $\begin{array}{l}\text { Reception of feedback from the members on the previous session } \\
\text { Explanation of the concept of "Here and Now" and its role in the group sessions } \\
\text { Encouragement of the members to concentrate on the here and now moment, and express their momentary feelings } \\
\text { Explanation of the "group as a small social example" by the group leader } \\
\text { Reception of the final feedback on the session and making conclusion }\end{array}$ & 90 minutes \\
\hline Forth & $\begin{array}{l}\text { Reception of feedback from the members on the previous session } \\
\text { Encouragement of the members to say the problems they have been dealing with from the past to the present and } \\
\text { want to share them with others in the group } \\
\text { In order to normalize and train the members, the group leader as the first person gives feedback on the problems of } \\
\text { the volunteer member, considering the group norms } \\
\text { The group leader encourages other members to give feedback on the problems of the volunteer Reception of the } \\
\text { final feedback on the session, and conclusion }\end{array}$ & 90 minutes \\
\hline Fifth & $\begin{array}{l}\text { Reception of feedback from the members on the previous session } \\
\text { Reviewing and conclusion of the problem of the previous session volunteer by the leader and other members (if } \\
\text { his/her problem needs more discussion, it will be further discussed considering time for others) } \\
\text { Review of the relationship among the leader and other members, and the volunteer member of the last session } \\
\text { during checking his/her problem (process) } \\
\text { Encouragement of the new volunteer to say his/her problem and to self-disclose } \\
\text { Reception of the final feedback on the session, and conclusion }\end{array}$ & 90 minutes \\
\hline Sixth & like the last session & 90 minutes \\
\hline Seventh & $\begin{array}{l}\text { Reception of feedback from the members on the previous session } \\
\text { Reviewing and conclusion of the problem of the previous session volunteer by the leader and other members (if } \\
\text { his/her problem needs more discussion, it will be further discussed considering time for others) } \\
\text { Reviewing the relationship among the leader and other members, and the volunteer member of the last session } \\
\text { during checking his/her problem (process) } \\
\text { Encouragement of the new volunteer to say his/her problem and to self-disclose (in final sessions, we usually ask } \\
\text { the members who revealed themselves: "why did you decide to discuss these issues with the group now?", then we } \\
\text { take this issue as a point to focus on the process more and more) } \\
\text { Reception of the final feedback on the session, and conclusion }\end{array}$ & 90 minutes \\
\hline $\begin{array}{l}\text { Eighth } \\
\text { Ninth }\end{array}$ & $\begin{array}{l}\text { like the last session } \\
\text { like the last session }\end{array}$ & $\begin{array}{l}90 \text { minutes } \\
90 \text { minutes }\end{array}$ \\
\hline Tenth & $\begin{array}{l}\text { Reception of feedback from the members on the previous session } \\
\text { Review and conclusion of the problem of the previous session volunteer by the leader and other members (if his/her } \\
\text { problem needs more discussion, it will be further discussed considering time for others) } \\
\text { Reviewing the relationship among the leader and other members, and the volunteer member of the last session } \\
\text { during checking his/her problem (process) } \\
\text { Encouragement of the members to review their relationship with other members from the moment when the group } \\
\text { started till now, and to give feedbacks to each other } \\
\text { Encouragement of the members to talk about the impacts this group had on their lives and problems } \\
\text { The final conclusion by the leader and wishing the bests for the members }\end{array}$ & 90 minutes \\
\hline
\end{tabular}

\section{Results}

This section is dedicated to the description and analysis report of the collected data. The first part provides descriptive data about the variables, including numbers, mean, standard deviation, and maximum and minimum scores for each variable. In the second part, decisions are made about the acceptance or ignorance of each hypothesis using appropriate statistical tests for the hypotheses. In this research, the desired analyses were carried out in SPSS software (version 24).

The descriptive data of each variable in the pre- test and post-test stages are reported separately for the sample and the control group in the tables. The data summarized in Table 2 show that the significance level of Z-values in the distribution of the scores of "resilience" and "meaning in life" for intervention and control groups is more than 0.05 both at pre-test and post-test stages $(\mathrm{P}>0.05)$. This means that the scores of the dependent variables had a normal distribution; hence, it was possible to use parametric tests to examine the research hypotheses. 
Table 2. The Kolmogorov-Smirnov test for checking the normality of distribution of the scores of variables

\begin{tabular}{|c|c|c|c|c|c|c|c|c|}
\hline \multirow{2}{*}{ Variable } & \multirow{2}{*}{ Group } & \multirow{2}{*}{ Test } & \multicolumn{3}{|c|}{ Most Extreme Differences } & \multirow{2}{*}{$\mathbf{Z}$} & \multirow{2}{*}{ Sig } & \multirow{2}{*}{$\begin{array}{c}\text { The state of } \\
\text { normality }\end{array}$} \\
\hline & & & Positive & Negative & Absolute & & & \\
\hline \multirow{4}{*}{ Resilience } & Experimental & Pre-test & 0.144 & -0.144 & 0.144 & 0.559 & 0.913 & Normal \\
\hline & group & Post-test & 0.240 & -0.160 & 0.240 & 0.929 & 0.354 & Normal \\
\hline & Control groun & Pre-test & 0.243 & -0.178 & 0.243 & 0.941 & 0.338 & Normal \\
\hline & Control group & Post-test & 0.227 & -0.215 & 0.227 & 0.880 & 0.421 & Normal \\
\hline \multirow{4}{*}{ Meaning in life } & Experimental & Pre-test & 0.155 & -0.125 & 0.155 & 0.602 & 0.862 & Normal \\
\hline & group & Post-test & 0.208 & -0.177 & 0.208 & 0.807 & 0.534 & Normal \\
\hline & & Pre-test & 0.222 & -0.222 & 0.134 & 0.860 & 0.450 & Normal \\
\hline & Control group & Post-test & 0.198 & -0.198 & 0.135 & 0.766 & 0.600 & Normal \\
\hline
\end{tabular}

Table 3. Results of the F-test for examination of the homogeneity of regression line slopes of the resilience scores between the two groups

\begin{tabular}{|c|c|c|c|c|c|c|}
\hline Component & Effects source & Sum of squares & Degrees of freedom & Mean squares & $\mathbf{F}$ & $\mathbf{P}$ \\
\hline \multirow{3}{*}{ Resilience } & Group $\times$ resilience pre-test & 0.011 & 1 & 0.011 & \multirow{3}{*}{0.011} & \multirow{3}{*}{0.918} \\
\hline & Error & 27.147 & 26 & 1.044 & & \\
\hline & Total & 599 & 30 & - & & \\
\hline
\end{tabular}

Table 4. Results of Levene's test for examination of the variance homogeneity of the resilience scores between the intervention and control groups

\begin{tabular}{lcccc}
\hline Variable & F & Degrees of freedom 1 & Degrees of freedom 2 \\
\hline Resilience & 2.662 & 1 & 28 & P \\
\hline
\end{tabular}

Table 5. Weighted mean and standard error of the resilience scores in the intervention and control groups

\begin{tabular}{lcccc}
\hline Variable group & & Intervention & & \\
\hline Resilience & $X$ & Standard error & Control & Standard error \\
& 32.68 & 0.65 & 0.65 & 25.61 \\
\hline
\end{tabular}

To confirm this assumption, the relation between the pre-test and post-test resilience scores of both groups should be the same. This assumption was examined by comparing the regression line slopes between the two groups and calculating the $\mathrm{F}$ value and its significance level. Unequal slopes indicate a correlation between pre-test and post-test stages which caused the results of the analysis of covariance to be delusive (Stivens, 1996; p. 323). Table 3 summarizes the results of the examination of this assumption.

Most of the parametric methods, including the analysis of covariance, are based on the assumption that the samples are obtained from the statistical population with the same variance. It means that the variance of the scores between the groups has no significant difference. Levene's test was used to examine this assumption. To confirm this assumption, the test should not be significant (the significance level should be more than 0.05). If the significance level is less than 0.05 , it means that the variances of the groups are not the same. If this assumption is violated, the analysis of covariance can be used only if the sizes of the groups are the same.

According to Table 4, Levene's test was used to determine the variance homogeneity of the resilience scores between the intervention and control groups. As it shows, the significance level of the $\mathrm{F}$ value was more than 0.05 ( $\mathrm{P}>0.05)$; hence, the assumption of variances homogeneity was confirmed.

According to the data given in Tables 4 and 5, the weighted mean of the resilience scores (the mean in which the effect of pre-test was controlled) in the intervention group is higher than that in the control group. The mean values of these scores in the intervention and control groups were 32.68 and 25.61 , respectively.

The results summarized in Tables 6 and 7 indicate

Table 6. Results of the univariate analysis of covariance on the resilience scores between the intervention and control groups.

\begin{tabular}{lcccc}
\hline Effect source & Sum of squares & Degrees of freedom & Mean squares & F \\
\hline Group & 373.66 & 1 & 373.66 & P \\
Error & 171.18 & 27 & 6.34 & 58.937 \\
Total & 27723 & 30 & - & 0.001 \\
\hline
\end{tabular}

Table 7. Results of univariate tests on the resilience scores between the intervention and control groups.

\begin{tabular}{|c|c|c|c|c|c|c|}
\hline Test & Value & $\mathbf{F}$ & Hypothesis degrees of freedom & Error degrees of freedom & $\mathbf{P}$ & $\eta 2$ \\
\hline Pillai & 0.967 & $29.352 * *$ & 14 & 16 & 0.001 & 0.702 \\
\hline Wilks' lambda & 0.069 & $29.352^{* *}$ & 14 & 16 & 0.001 & 0.702 \\
\hline Hoteling & 23.387 & 29.352 & 14 & 16 & 0.001 & 0.702 \\
\hline \multirow[t]{2}{*}{ Roy's Largest Root } & 23.387 & $29.352 * *$ & 14 & 16 & 0.001 & 0.702 \\
\hline & & & & & \multicolumn{2}{|c|}{$* * \mathrm{P}<0.01$} \\
\hline
\end{tabular}


Table 8. Box's M test for examining the homogeneity of the covariance matrix

\begin{tabular}{lcccc}
\hline Box's M test & F & Degrees of freedom 1 & Degrees of freedom 2 & P \\
\hline 93.563 & 1.345 & 45 & 2575 & 0.063 \\
\hline
\end{tabular}

Table 9. Results of the univariate tests on the meaning in life scores between the intervention and control groups

\begin{tabular}{|c|c|c|c|c|c|c|}
\hline Test & Value & $\mathbf{F}$ & Hypothesis degrees of freedom & Error degrees of freedom & $\mathbf{P}$ & $\eta 2$ \\
\hline Pillai & 0.959 & $28.766^{* *}$ & 14 & 16 & 0.001 & 0.635 \\
\hline Wilks' lambda & 0.041 & $28.766^{* *}$ & 14 & 16 & 0.001 & 0.635 \\
\hline Hoteling & 23.536 & $28.766^{* *}$ & 14 & 16 & 0.001 & 0.635 \\
\hline Roy's Largest Root & 23.536 & $28.766^{* *}$ & 14 & 16 & 0.001 & 0.635 \\
\hline & & & & & \multicolumn{2}{|c|}{$* * \mathrm{P}<0.01$} \\
\hline
\end{tabular}

that the calculated $\mathrm{F}$ value for the mean difference of the resilience scores between the intervention and control groups was 58.94. Moreover, the significance level of this value with the degree of freedom of 1 and 31 was less than 0.05 (F [1 and 27] $=58, \mathrm{P}=0.001)$. Therefore, the difference in the mean values of the resilience scores between the intervention and control groups was significant. Hence, it can be said with 95\% confidence that the Yalom group therapy had a significant impact on increasing the resilience of the nurses and supports the first hypothesis. According to the value of the eta-squared, this impact was about $69 \%$.

As shown in Table 8, the statistic value of the Box's $\mathrm{M}$ was 93.563 and the $\mathrm{F}$ value for this statistic was 1.345. The calculated significance level of the $F$ value was 0.06 which is more than 0.05 ( $\mathrm{P}>0.05)$. Therefore, the hypothesis of the homogeneity of the covariance matrix is accepted.

According to the data given in Table 9, the value of the Wilks' lambda was 0.041 and the calculated $F$ value in this statistic was 28.766. The significance level of this value (according to the degree of freedom of 15 and 17) was less than 0.05 $(\mathrm{P}>0.05)$. Therefore, the difference in the mean values is significant and it can be said that the Yalom group therapy affected the meaning in life. According to the value of the eta-squared, this impact was about $64 \%$.

\section{Discussion}

The present research aimed to study the effectiveness of the Yalom group therapy on the resilience and meaning in life of the nurses. For this purpose, 32 nurses who were caring for the Covid19 patients in the hospitals of Hamedan in 2020 were selected by random sampling and according to the inclusion criteria. They were equally divided into two groups of intervention and control. Afterward, the subjects were asked to complete the ConnorDavidson's Resilience Questionnaire (2003) and Steger's Meaning in Life Questionnaire (2006) at pre-test and post-test stages. In the end, the resilience score and the communication skills of each subject at the pre-test and post-test stages were summed up and compared to each other and the extent of their correlation was analyzed.

The results indicated that before and after the intervention, the mean values and the standard deviation of the resilience and communication questionnaires scores had been increased in the intervention group. However, no changes were observed in this regard in the control group.

The COVID-19 epidemic has led to fear, anxiety, and stress all around the world. Meantime, the medical staff, including the nurses who are more exposed to the adverse mental effects of long working hours and high workload [2], are in dire need of receiving proper psychological services to avoid exhaustion, stay motivated, and withstand the adversity. To have a strong and rich "meaning" in life is one of the most important psychological factors which can help people maintain their morale and motivation [16].

In group therapy for the mental healthcare staff in Sweden, it was found that the feeling of belonging, mutual support, understanding, and self-revaluation, which are the results of intragroup processes, can influence the life meaningfulness of the members [17]. Self-disclose, giving friendly feedbacks, and sharing the problems are the most important features of group therapy that probably can help people improve their search for meaning and resilience [10].

A few studies have focused only on the effects of emotional support of intragroup and intergroup dynamics on resilience. For instance, in the research conducted by Haddadi and Ebrahimi, the impact of the Yalom group therapy, which is based on the dynamics of the groups, was examined on the communication skills and resilience of the psychology students and significant changes were observed [18]. Due to these studies, our research team decided to evaluate the extent of the positive impacts of this treatment method on the nurses who were under high mental pressure during the COVID-19 epidemic.

\section{Conclusions}

Results of this study indicated that the Yalom 
group therapy for 10 sessions could have a significant impact on the resilience level and meaning in life of the nurses. The medical staff seriously needs to maintain and empower their mental health, especially in particular situations, such as the Coronavirus epidemic and other possible epidemics in the future. Therefore, the results of this study can be used to maintain the health of the healthcare staff in such situations. The limitation of our research was that it was only performed in one medical center. It is suggested that a similar study be carried out in other medical centers as well.

\section{Ethical Considerations}

Following ethical guidance, written consent was obtained from the participants.

\section{Authors' contributions}

All authors contributed to preparing this article.

\section{Funding/Support \\ None declared}

\section{Conflicts of interest}

The authors declare no conflicts of interest.

\section{References}

1. Naushad VA, Bierens JJ, Nishan KP, Firjeeth CP, Mohammad $\mathrm{OH}$, Maliyakkal AM, et al. A systematic review of the impact of disaster on the mental health of medical responders. Prehospital and Disaster Medicine. 2019; 34(6):632-43. [DOI:10.1017/S1049023X19004874] [PMID]

2. Cai H, Tu B, Ma J, Chen L, Fu L, Jiang Y, et al. Psychological impact and coping strategies of frontline medical staff in Hunan between January and March 2020 during the outbreak of coronavirus disease 2019 (COVID) in Hubei, China. Medical Science Monitor. 2020; 26:e924171. [DOI:10.12659/MSM.924171] [PMID] [PMCID]

3. Rana W, Mukhtar S, Mukhtar S. Mental health of medical workers in Pakistan during the pandemic COVID-19 outbreak. Asian Journal of Psychiatry. 2020; 51:102080. [DOI:10.1016/j.ajp.2020.102080] [PMID] [PMCID]

4. Hadden BW, Smith CV. I gotta say, today was a good (and meaningful) day: Daily meaning in life as a potential basic psychological need. Journal of Happiness Studies. 2019; 20(1):185-202. [DOI:10.1007/s10902-017-9946-y]

5. Steger MF, Frazier P, Oishi S, Kaler M. The meaning in life questionnaire: assessing the presence of and search for meaning in life. Journal of Counseling Psychology. 2006; 53(1):80. [DOI:10.1037/0022-0167.53.1.80]

6. Baltaci A, Soykan SN. Optimism, happiness, life meaning and life satisfaction levels of the faculty of divinity students: a multi-sample correlational study. Spiritual Psychology and Counseling. 2020; 5(2):167-84.

7. Choi KW, Stein MB, Dunn EC, Koenen KC, Smoller JW. Genomics and psychological resilience: a research agenda. Molecular Psychiatry. 2019; 24(12):1770-8. [DOI:10.1038/s41380-019-0457-6] [PMID] [PMCID]

8. Yamaguchi S, Kawata Y, Shibata N, Hirosawa M. Direct and indirect effect of hardiness on mental health among Japanese University Athletes. International Conference on Applied Human Factors and Ergonomics. Cham: Springer; 2017.

9. Ebrahimi M, Hamian Z, Yarahmadi Y, Jadidi H, Ahmadiyan $H$. The effectiveness of positive psychology training on the resiliency and job satisfaction of government employees. International Journal of Behavioral Sciences. 2020; 14(2):79 84. [DOI:10.30491/IJBS.2020.206270.1153]

10. Yalom ID, Leszcz M. The theory and practice of group psychotherapy. Paris, France: Hachette Livre; 2020.

11. Connor KM, Davidson JRT. Development of a new resilience scale: the connor-davidson resilience scale (CDRISC). Depress Anxiety. 2003; 18(2):76-82. [DOI:10.1002/da.10113] [PMID]

12. Bigdeli I, Najafy M, Rostami M. The relation of attachment styles, emotion regulation, and resilience to well-being among students of medical sciences. Iranian Journal of Medical Education. 2013; 13(9):721-9.

13. Aliakbari Dehkordi M, Peymanfar E, Mohtashami T, Borjali A. The comparison of different levels of religious attitude on sense of meaning, loneliness and happiness in life of elderly persons under cover of social wlfare organisation of Urmia city. Iranian Journal of Ageing. 2015; 9(4):297-305.

14. Mesrabadi J, Jafariyan S, Ostovar N. Discriminative and construct validity of meaning in life questionnaire for Iranian students. International Journal of Behavioral Sciences. 2013; 7(1):83-90.

15. Yalom I. The Schopenhauer cure. New York: Harper Perennial; 2006.

16. Costin V, Vignoles VL. Meaning is about mattering: Evaluating coherence, purpose, and existential mattering as precursors of meaning in life judgments. Journal of Personality and Social Psychology. 2020; 118(4):864-84. [DOI:10.1037/pspp0000225] [PMID]

17. Lund K, Argentzell E, Leufstadius C, Tjurnstrand C, Eklund $M$. Joining, belonging, and re-valuing: a process of meaning-making through group participation in a mental health lifestyle intervention. Scandinavian Journal of Occupational Therapy. 2019; 26(1):55-68. [DOI:10.1080/ 11038128.2017.1409266] [PMID]

18. Haddadi A, Ebrahimi ME. The effect of yalom group therapy on resiliency and communication skills in students. Health Research Journal. 2020; 5(3):188-98. [DOI:10.29252/hrjbaq.5.3.188] 